\title{
Desenvolvimento de Vigna unguiculata (L.) Walp submetidas a concentrações de compostagens laminar e bovina
}

Este trabalho teve como objetivo avaliar o desenvolvimento de feijão-de-corda (Vigna unguiculata) sob dois sistemas de compostagens em diferentes concentrações, sendo a primeira a base de folha, serrapilheira e terra, já a segunda à base de esterco bovino, cinzas e terra. Para confecção do experimento foram utilizados resíduos como sacos, caixotes entre outros, para a produção da composteira. Após os preparados dos tratamentos, estes foram diluídos em areia proporcionando as concentrações de 25, 50, 75 e 100\% (volume de areia/volume do composto), onde foram colocados em recipientes do tipo PET e utilizados sementes de feijão para condução das avaliações. Foram realizadas avaliações semanais após a germinação de cada planta, sendo coletada a altura em centímetro $(\mathrm{cm})$ em intervalos semanais. Os dados demonstraram que as concentrações provenientes de serrapilheiras apresentaram maiores crescimentos, sendo que a concentração de $75 \%$ teve o melhor crescimento, independentemente do tipo de compostagem. É possível observar que a partir dos 42 a 49 dias, os resultados dos tratamentos começaram a apresentar diferenças significativa, sendo ainda constatadas que nas curvas de crescimento, essas avaliações foram as que apresentaram maiores taxas de desenvolvimento entre as mensurações. Recomenda se para o cultivo do feijão-de-corda compostagem a base de serrapilheira.

\section{Development of Vigna unguiculata (L.) Walp submitted to concentrations of laminar and bovine composting}

\begin{abstract}
The objective of this work was to evaluate the development of string bean (Vigna unguiculata) under two composting systems in different concentrations, the first one being leaf, litter and ground, the second being the base of cattle manure, ash and Earth. For the preparation of the experiment were used waste such as bags, crates and others, for the production of the compost. After the treatment preparations, they were diluted in sand to give the concentrations of $25,50,75$ and $100 \%(\mathrm{v} / \mathrm{v})$, where they were placed in PET containers and bean seeds were used to conduct the evaluations. Weekly evaluations were performed after the germination of each plant, and the height in centimeter $(\mathrm{cm})$ was collected at weekly intervals. The data showed that the concentrations of insecticides showed higher growth, being the concentration of $75 \%$ had the best growth, independently of the type of compost. It is possible to observe that from the 42 to 49 days, the results of the treatments began to differ significantly, being also found that in the growth curves, these evaluations were those that presented the highest rates of development among the measurements. It is recommended for the cultivation of the bean-of-rope composting the base of mats.
\end{abstract}

Keywords: Plant Nutrition; Development; Organic Solid Waste; String Beans.

Topic: Ciências do Solo

Reviewed anonymously in the process of blind peer
Received: $02 / 03 / 2020$

Approved: $20 / 04 / 2020$
Patricia Paz da Costa

Universidade de Cuiabá, Brasil

patycolgel@hotmail.com

Marcelo Dias de Souza (D)

Universidade de Cuiabá, Brasil

http://lattes.cnpq.br/9474670068485343

http://orcid.org/0000-0002-4348-4645

marcelo.dias@florestal.eng.br

Alexandre Roman Parada

Universidade de Cuiabá, Brasil

http://lattes.cnpq.br/0281344336604192

engambiental.sst@gmail.com

\author{
Roberta Daniela de Souza (iD \\ Universidade de Cuiabá, Brasil \\ http://lattes.cnpq.br/6695057034861231 \\ http://orcid.org/0000-0001-7268-2694 \\ roberta.engenhariaambiental@gmail.com \\ Pricila Juliana de Souza \\ Universidade de Cuiabá, Brasil \\ http://lattes.cnpq.br/1774304263302532 \\ http://orcid.org/0000-0002-6695-2261 \\ souza.pricila123@gmail.com
}

Referencing this:

COSTA, P. P.; SOUZA, M. D.; PARADA, A. R.; SOUZA, R. D.; SOUZA, P. J.. Desenvolvimento de Vigna unguiculata (L.) Walp submetidas a concentrações de compostagens laminar e bovina. Revista Ibero Americana de Ciências Ambientais, v.11, n.3, p.1-9, 2020. DOI: http://doi.org/10.6008/CBPC2179-6858.2020.003.0001 


\section{INTRODUÇÃO}

A compostagem é um processo utilizado para transformar diferentes tipos de resíduos orgânicos em adubo, quando incorporado ao solo promove o enriquecimento das propriedades físico-químicas e biológicas, propiciando a redução do uso de fertilizantes químicos na agricultura, a proteção que a matéria orgânica proporciona ao solo contra o processo de degradação bem como na redução do lixo depositado em aterros sanitários (SANTOS et al., 1990).

A compostagem é um processo dirigido e controlado pelo homem, onde os resíduos orgânicos por sua vez que não tem praticamente nenhum valor, são transformados em produto de valor agrícola, económico e também ambiental (ECOLE et al., 2015). Essa técnica foi desenvolvida com a finalidade de acelerar com qualidade a estabilização (também conhecida como humificação) da matéria orgânica, visto que na natureza a humificação ocorre sem prazo definido, dependendo das condições ambientais e da qualidade dos resíduos orgânicos (OLIVEIRA et al., 2005).

Geralmente esse processo é realizado por meio da decomposição microbiana, de oxidação e oxigenação de uma massa heterogênea de matéria orgânica, em que ocorre decomposição aeróbica dos resíduos orgânicos por populações microbianas. Assim é ideal que as condições ambientais sejam ideais para que os microrganismos decompositores se desenvolvam, (temperatura, umidade, aeração, pH, tipo de compostos orgânicos existentes e tipos de nutrientes disponíveis), pois utilizam essa matéria orgânica como alimento e sua eficiência baseia-se na interdependência e inter-relacionamento desses fatores.

A compostagem deve ser necessariamente aeróbia e incluir uma fase termofílica (45 - 65 ํㅡ), maximizando a atividade microbiológica de degradação e higienização (primeira fase do processo), e a fase de maturação ou cura, quando ocorrem a humificação e a produção do composto propriamente dito, que é a segunda fase do processo (PEREIRA NETO et al., 1992). Ainda segundo os autores supracitados, a compostagem é o processo de tratamento de resíduos que apresenta maior flexibilidade operacional, combinando baixo custo e alta eficiência em um só sistema.

A importância da adubação orgânica em agricultura é amplamente reconhecida, visando compensar as perdas de nutrientes ocorridas durante seu cultivo, havendo maior aumento na produção ao utilizar-se esterco bovino (KIMOTO, 1993). A compostagem vem sendo um processo de reciclagem da matéria orgânica que tende a dar um destino adequado para os resíduos orgânicos, evitando sua acumulação em aterros e melhorando a estrutura dos solos. $\mathrm{O}$ uso da compostagem de resíduos agropecuários é uma técnica que vem sendo oferecida para se obter a rápida estabilização da matéria orgânica.

Para Souto et al. (2005), a maior parte dos solos das regiões tropicais apresenta baixa fertilidade natural, devido principalmente aos baixos teores de matéria orgânica e de nutrientes disponíveis. Ainda segundo os autores, os resíduos orgânicos podem ser aplicados ao solo para aumentar o teor de nutrientes disponíveis para as plantas ainda, caso sejam aplicadas doses frequentes ao longo dos anos, podem incrementar o teor de carbono orgânico total no solo, especialmente naqueles com histórico de degradação.

Nesse contexto, o presente trabalho teve como objetivo avaliar o desenvolvimento do feijão-de- 
corda (Vigna unguiculata (L.) Walp) submetidos a dois tipos de compostagem, orgânica e laminar e em diferentes concentrações do volume do composto.

\section{MATERIAIS E MÉTODOS}

O experimento foi realizado no Horto Florestal, localizado na Rua Ivan Rodrigues Arraes, s/n - Coxipó da Ponte, Cuiabá - MT, 78085-055, localizada próximo ao centro da cidade de fácil acesso, contando com uma área de aproximadamente 15 hectares. O clima predominante é o Aw Koppen, tropical continental, podendo variar entre o tropical continental úmido nos meses chuvosos, e o tropical continental seco nos meses de estiagem. A temperatura média anual fica na faixa de $27^{\circ} \mathrm{C}$ (DUARTE et al., 2003).

Os tratamentos foram realizados no local em campo aberto e sombreado por árvores, onde foram preparados dois tipos compostagem: sendo a primeira proveniente de serrapilheira, folhas de taboca e solo, já a segunda proveniente de adubo bovino, cinzas e solo, sendo que ambos foram colocados em um recipiente e irrigado a cada 48 horas até chegar à decomposição desejada.

Para os dois sistemas foram utilizadas diferentes quantidades de cada componente, sendo que na primeira compostagem foram confeccionados com $40 \%$ de serapilheira, $40 \%$ de folhas de taboca e $20 \%$ de solo, já para o segundo tipo de compostagem foram utilizados $50 \%$ de adubo bovino, $30 \%$ de cinzas e $20 \%$ de solo.

O recipiente utilizado para a compostagem consistiu em caixotes de supermercados e revestidos de sacos de ração, visando o reaproveitamento e para que não houvesse vazamentos de matéria. A irrigação e o reviramento da compostagem foram realizados com a ajuda de uma pá de madeira depois de sete dias do início do experimento. Para o experimento foram utilizados recipientes de garrafas pets de dois litros e meio, sendo estes coletados em residências próximos ao local, da qual foram lavados e confeccionados deixando $13 \mathrm{~cm}$ de altura (Figura 1).

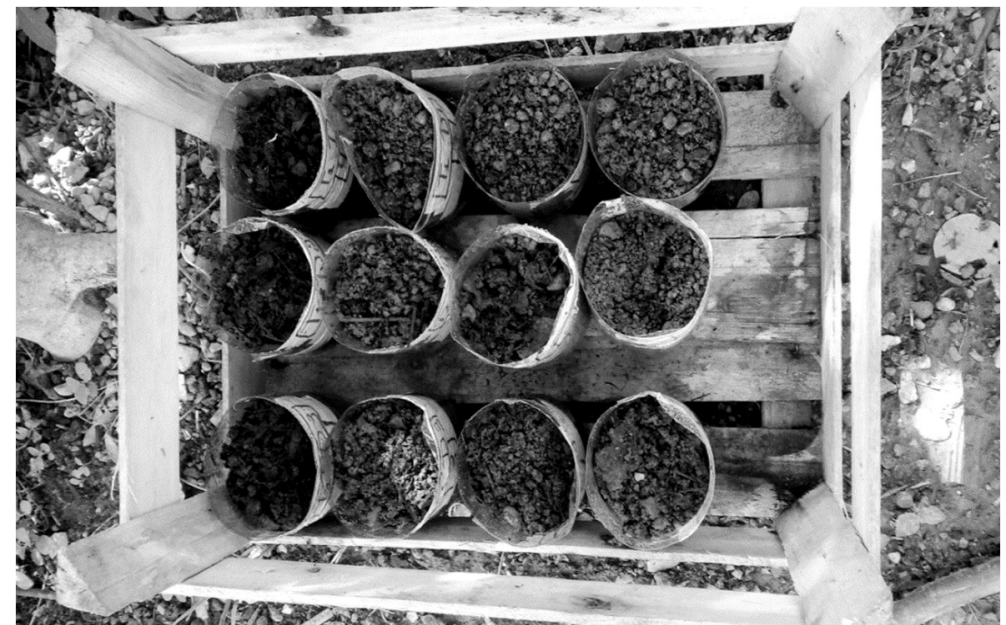

Figura 1: Plásticos do tipo PET confeccionado para utilização no experimento de semeadura e adubação com compostagem. Horto Florestal, Cuiabá/MT, 2018.

Para estabelecer as concentrações de adubação, os tratamentos foram diluídos em areia, sendo considerados seus respectivos volumes para estabelecimento das concentrações de 25, 50, 75 e 100\% (v/v). Também foi preparado um tratamento contendo apenas areia para representar o tratamento controle (0\%). 
Foi mensurado o crescimento em altura de cada planta e em intervalos semanais, até o período de 90 dias, utilizando uma fita métrica graduada. Durantes as avaliações estes foram irrigadas duas vezes ao dia no período matutino e vespertino, $7 \mathrm{~h}$ e $18 \mathrm{~h}$ respectivamente.

Para o teste de desenvolvimento fora utilizado sementes de feijão-de-corda (Vigna unguiculata (L.) Walp), provenientes Horto Florestal, onde foram plantadas três sementes em cada recipiente, sendo estes observados até a germinação.

Os dados da pesquisa foram submetidos à análise de variância ANOVA, sendo analisado em delineamento de inteiramente casualizados (DIC), em que para cada intervalo de avaliação foi efetuado uma análise, incluindo o tratamento testemunha. Com intuito de avaliar a interação dos fatores concentrações $X$ compostagem, os dados da última avaliação (49 dias) foram dispostos em esquema fatorial 2x4 (compostagem $x$ concentração). As análises foram efetuadas com quatro repetições por tratamento. Quando constatado diferenças significativas, estes foram comparadas pelo teste de Tukey, ao nível de $5 \%$ de probabilidade de erro.

Com o intuito de analisar o desenvolvimento das mudas em relação às concentrações dos tipos de compostagem, os dados foram ajustados por meio de modelo de regressão linear, contendo como variável independente e dependente a concentração dos compostos e altura respectivamente. A significância das regressões foi obtida por meio do teste da hipótese nula, em que para a escolha da equação polinomial adequada, foi considerada a regressão com menor probabilidade de erro e maior coeficiente de determinação $\left(r^{2}\right)$. As análises estatísticas foram realizadas por meio do software R (R CORE TEAM, 2019).

\section{RESULTADOS E DISCUSSÃO}

Para compostagem de serrapilheira foram necessários 82 dias para a decomposição. Pode-se constatar que a partir da terceira mensuração (21 dias) a concentração de 50 e 100 foram as que apresentaram as maiores médias de crescimento, entretanto a partir das demais leituras, todas as concentrações apresentaram crescimento igual estatisticamente, exceto para tratamento controle, da qual obteve sempre a menor média de crescimento em todas as mensurações realizadas (Tabela 1).

Tabela 1: Crescimento em altura $(\mathrm{cm})$ das mudas de feijão de corda submetido aos tratamentos de adubação de compostagem de serrapilheira em função das concentrações.

\begin{tabular}{|l|l|l|l|l|l|l|l|}
\hline \multirow{2}{*}{ Doses } & \multicolumn{1}{l|}{ Período de avaliação } & 14 & 21 & 28 & 35 & 42 \\
\cline { 2 - 7 } & 7 & 7,5 & $14,7 \mathrm{c}$ & $20,2 \mathrm{~b}$ & $25,2 \mathrm{~b}$ & $29,5 \mathrm{~b}$ \\
\hline Controle & 4,5 & 10,3 & $27,7 \mathrm{~b}$ & $36,2 \mathrm{a}$ & $40,5 \mathrm{a}$ & $47,5 \mathrm{a}$ \\
\hline 25 & 5,5 & 13,2 & $31,1 \mathrm{a}$ & $38,1 \mathrm{a}$ & $42,5 \mathrm{a}$ & $45,5 \mathrm{a}$ \\
\hline 50 & 7,1 & 12,1 & $31,5 \mathrm{ab}$ & $39,2 \mathrm{a}$ & $43,1 \mathrm{a}$ & $47,5 \mathrm{a}$ \\
\hline 75 & 5,5 & 13,5 & $31,2 \mathrm{a}$ & $38,2 \mathrm{a}$ & $41,1 \mathrm{a}$ & $43,1 \mathrm{a}$ \\
\hline 100 & 10,1 & 18,68 & 11,08 & 9,06 & 8,07 & $50,2 \mathrm{a}$ \\
\hline $\mathrm{CV}(\%)$ & 27,18 & $0,16 \mathrm{~ns}$ & $\begin{array}{l}0,00 \\
* *\end{array}$ & $\begin{array}{l}0,00 \\
* *\end{array}$ & $\begin{array}{l}0,00 \\
* *\end{array}$ & $\begin{array}{l}0,00 \\
* *\end{array}$ \\
\hline$P \alpha$ & $0,23 \mathrm{~ns}$ & & $\begin{array}{l}0,00 \\
* *\end{array}$ &
\end{tabular}

\footnotetext{
ns Não significativo
}

* Significativo ao nível de $1 \%$ de probabilidade.

Médias seguidas de mesma letra na vertical não diferem estatisticamente entre si, pelo teste de Tukey ao nível de $5 \%$ de probabilidade de erro. 
De acordo com Schwengber et al. (2007), a compostagem a base de serrapilheira é conhecida como compostagem laminar, sendo inspirada nos processos naturais, mais propriamente a degradação da serrapilheira das matas. Ainda segundo os autores, o material é depositado sobre o solo, todos os processos fermentativos são aeróbios, sendo criado um ambiente muito propício para o desenvolvimento da fauna edáfica, como minhocas, colêmbolos, ácaros, insetos diversos e, principalmente, microvida (fungos, bactérias e actinomicetos).

A serapilheira atua na superfície do solo como um sistema de entrada e saída, que tende a receber entrada via vegetação e, por sua vez, decompondo-se e suprindo o solo e as raízes com nutrientes e matéria orgânica, sendo essencial na restauração da fertilidade do solo em áreas em início de sucessão ecológica (EWEL, 1976).

Em relação à compostagem bovina, foram necessários 12 dias para a decomposição, ou seja, menor tempo em relação a compostagem vegetal. O processo de caracterização por fatores de estabilização e maturação pode variar de poucos dias a várias semanas, dependendo do ambiente (TEIXEIRA, 2002). A velocidade de decomposição do material orgânico depende da facilidade com que esse material pode ser decomposto, de suas características químicas e do $\mathrm{pH}$ do meio onde este se encontra. Materiais baseado em celulose é decomposto três vezes mais rápido em relação às partes lenhosas ricas em taninos (LARCHERL, 2000).

As concentrações de compostagem bovina influenciaram no crescimento em altura das mudas, pois desde a primeira mensuração se observou crescimento diferenciado entre as concentrações, principalmente em relação ao controle (testemunha), entretanto foi só a partir da quarta avaliação (vigésimo 28 dias) que demonstrou ter crescimento significativo, sendo constatado que a concentração de $75 \%$ obteve maior crescimento (Tabela 2). Em relação ao controle, é possível observar menor crescimento, sendo observada a menor média no final das mensurações.

Tabela 2: Crescimento em altura $(\mathrm{cm})$ das mudas de feijão de corda submetido aos tratamentos de adubação de compostagem bovino em função das concentrações.

\begin{tabular}{|c|c|c|c|c|c|c|c|}
\hline \multirow[t]{2}{*}{ Doses } & \multicolumn{7}{|c|}{ Período de avaliação } \\
\hline & 7 & 14 & 21 & 28 & 35 & 42 & 49 \\
\hline Controle & 4,5 & 9,5 & 14,7 & $20,5 \mathrm{~b}$ & $25,5 \mathrm{~b}$ & $29,2 \mathrm{~b}$ & $34,7 \mathrm{c}$ \\
\hline 25 & 4,5 & 10,25 & 18,2 & $21,5 a b$ & $26,2 \mathrm{~b}$ & $35,5 a b$ & $43,1 \mathrm{~b}$ \\
\hline 50 & 4,1 & 12,2 & 17,1 & $20,1 \mathrm{~b}$ & $24,5 \mathrm{~b}$ & $39,1 a b$ & $44,1 \mathrm{~b}$ \\
\hline 75 & 5,2 & 14,2 & 22,5 & $26,5 \mathrm{a}$ & $34,1 \mathrm{a}$ & $43,6 a b$ & $50,5 \mathrm{a}$ \\
\hline 100 & 5,5 & 12,1 & 18,5 & $20,2 \mathrm{~b}$ & $27,1 \mathrm{~b}$ & 39,1 a & $42,2 \mathrm{~b}$ \\
\hline $\mathrm{CV}(\%)$ & 27,35 & 16,23 & 13,57 & 12,88 & 11,02 & 9,99 & 5,33 \\
\hline$P \alpha$ & $\begin{array}{l}0,36 \\
\mathrm{~ns}\end{array}$ & $\begin{array}{l}0,23 \\
\mathrm{~ns}\end{array}$ & $\begin{array}{l}0,10 \\
\mathrm{~ns}\end{array}$ & $\begin{array}{l}0,00 \\
* *\end{array}$ & $\begin{array}{l}0,001 \\
* *\end{array}$ & $\begin{array}{l}0,003 \\
* *\end{array}$ & $\begin{array}{l}0,00 \\
* *\end{array}$ \\
\hline
\end{tabular}

ns Não significativo.

* Significativo ao nível de $1 \%$ de probabilidade.

Médias seguidas de mesma letra na vertical não diferem estatisticamente entre si, pelo teste de Tukey ao nível de $5 \%$ de probabilidade de erro.

Os dejetos advindos de compostagem bovina se tornam um grande problema quando destinados de maneira inadequada, segundo Konzen et al. (2009), um bovino produz de esterco (fezes e urina) cerca de $10 \%$ de sua massa corporal, aproximadamente 46 kg/vaca/dia. Silva et al. (2004) trabalhando com aplicação 
de esterco bovino em compostagem em algumas plantações, observou que o composto promove incremento nos teores de fósforo e potássio no solo além do aumento na produtividade, e da melhor retenção de água como escoamento superficial e filtração do solo, desta forma tendo positividade no desenvolvimento das plantações.

Em relação ao desenvolvimento das mudas de feijão, percebe se que o coeficiente de variação que ao longo da análise foi diminuindo, demonstrando que durante as avaliações as mudas de feijão começaram a ter desenvolvimento semelhante entre as repetições, diminuindo a variabilidade entre as amostras, fato constatado para os dois sistemas de compostagem analisados.

As analises estatísticas foram significativas e apresentaram probabilidade de erro menor que $1 \% \mathrm{e}$ ainda com coeficiente de variação menor que $15 \%$, sendo que na última mensuração esses valores foram menores que $10 \%$, da qual a análise de relação entre os fatores concentração x compostagem, constatou-se diferença significativa em ambos os tipos de compostagem, sendo que para a bovina, a concentração de $75 \%$ propiciou maior crescimento significativo, já para a compostagem à base de serrapilheira, independente das concentrações, o crescimento foi estatisticamente igual (Tabela 3).

Tabela 3: Analise fatorial entre os fatores concentração x compostagem no crescimento em altura (cm) das mudas de feijão de corda submetido aos tratamentos nos 49 dias de avaliação.

\begin{tabular}{|c|c|c|c|c|}
\hline \multirow{3}{*}{$\begin{array}{l}\text { Dose } \\
25 \\
\end{array}$} & \multicolumn{4}{|c|}{ Tipo de compostagem } \\
\hline & \multicolumn{2}{|c|}{ Bovino } & \multicolumn{2}{|c|}{ Serrapilheira } \\
\hline & 43,1 & b B & 50,5 & a A \\
\hline 50 & 44,1 & $a b B$ & 51,1 & $\mathrm{aA}$ \\
\hline 75 & 50,2 & a A & 50,5 & a A \\
\hline 100 & 42,2 & $\mathrm{bB}$ & 50,2 & a A \\
\hline $\mathrm{CV}(\%)$ & \multicolumn{4}{|c|}{7,26} \\
\hline$P \alpha$ & \multicolumn{4}{|c|}{$0,008 * *$} \\
\hline
\end{tabular}

** Significativo ao nível de $1 \%$ de probabilidade.

Médias seguidas de mesma letra na minúscula vertical e maiúscula na horizontal não diferem estatisticamente entre si, pelo teste de Tukey ao nível de $5 \%$ de probabilidade de erro.

Embora as concentrações da compostagem a base de serrapilheira não apresentaram diferenças significativas, entretanto na comparação entre os tipos de compostagem apresentou superioridade em todas as concentrações, portanto o mais adequado para $V$. unguiculata. Ao utilizar a serrapilheira, restos vegetais que recobrem a terra nas matas, propicia no aumento da quantidade de organismos decompositores no mesmo, desta forma favorece o processo de compostagem e consequentemente na nutrição vegetal.

Com os valores expressivamente altos de serrapilheira depositados no solo, permitem a formação de reservatório de matéria orgânica e nutrientes, essencial para o processo de revegetação (MARINHO et al., 2004). Higa et al. (1991) relatam que no processo de confecção do adubo orgânico, esses microrganismos agem sobre a matéria fermentando-a, onde ocorrendo produção de ácidos orgânicos, vitaminas, enzimas, aminoácidos e polissacarídeos que são importantes para o desenvolvimento vegetal.

Em relação ao desenvolvimento dos feijões, foi possível ajustar modelos lineares que explicaram o desenvolvimento das variáveis em função das concentrações e tempo, sendo que para os dois tipos de compostagem, o crescimento foi explicado por funções exponencial, da qual foi possível observar que os a maioria dos coeficientes foram estatisticamente significativos com nível de probabilidade de erro inferior a 
$5 \%$ (Tabela 4).

Tabela 4: Coeficientes das equações lineares para estimativa do crescimento em altura para as concentrações em função do tempo para compostagem bovina (BV), serrapilheira (SR) e testemunha utilizada nas plantas de feijão.

\begin{tabular}{|l|l|l|l|l|l|l|}
\hline Tratamentos & Regressão & $B_{0}$ & $B_{1}$ & $B_{2}$ & $r^{2}$ & $p$-value \\
\hline \multirow{5}{*}{ BV } & Doses & $34,47^{* *}$ & $0,41^{* *}$ & $-0,0031^{* *}$ & 0,68 & $2,03 \times 10^{-5}$ \\
\cline { 2 - 7 } & 25 & $0,46^{*}$ & $0,64^{*}$ & $0,0043^{\text {ns }}$ & 0,92 & $4,21 \times 10^{-15}$ \\
\cline { 2 - 7 } & 50 & $2,17^{\text {ns }}$ & $0,44^{*}$ & $0,0086^{*}$ & 0,91 & $1,87 \times 10^{-14}$ \\
\cline { 2 - 7 } & 75 & $5,35^{*}$ & $0,72^{* *}$ & $0,0041^{\text {ns }}$ & 0,96 & $2,21 \times 10^{-16}$ \\
\cline { 2 - 7 } & 100 & $1,78^{\text {ns }}$ & $0,59^{* *}$ & $0,0051^{*}$ & 0,95 & $2,12 \times 10^{-16}$ \\
\hline \multirow{5}{*}{ SR } & Doses & $36,52^{* *}$ & $0,49^{* *}$ & $-0,0037^{* *}$ & 0,63 & $7,12 \times 10^{-5}$ \\
\cline { 2 - 7 } & 25 & $-7,53^{* *}$ & $1,98^{* *}$ & $-0,016^{* *}$ & 0,95 & $2,20 \times 10^{-16}$ \\
\cline { 2 - 7 } & 50 & $-0,32^{*}$ & $1,82^{* *}$ & $-0,016^{* *}$ & 0,96 & $2,21 \times 10^{-15}$ \\
\cline { 2 - 7 } & 75 & $-9,35^{* *}$ & $2,40^{* *}$ & $-0,024^{* *}$ & 0,97 & $2,20 \times 10^{-16}$ \\
\cline { 2 - 7 } & 100 & $2,68^{\text {ns }}$ & $1,61^{* *}$ & $-0,013^{* *}$ & 0,92 & $1,57 \times 10^{-15}$ \\
\hline- & Testemunha & $-1,14^{*}$ & $0,79^{* *}$ & $0,0013^{\text {ns }}$ & 0,96 & $2,2 \times 10^{-16}$ \\
\hline
\end{tabular}

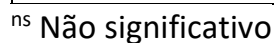

* Significativo ao nível de $5 \%$ de probabilidade.

** Significativo ao nível de $1 \%$ de probabilidade.

Os coeficientes de determinação $\left(r^{2}\right)$ dos modelos ajustados para a altura variou de 0,63 a 0,97 , sendo que apenas dois ajustes foram menores que 0,9 (altura em função da concentração) demonstrando que a curva de crescimento para as equações ajustadas apresenta menor variabilidade entre o valor real e ajustado. Assim na curva de crescimento constatou que algumas concentrações apresentaram comportamento semelhante no desenvolvimento em função do tempo (Figura 2).

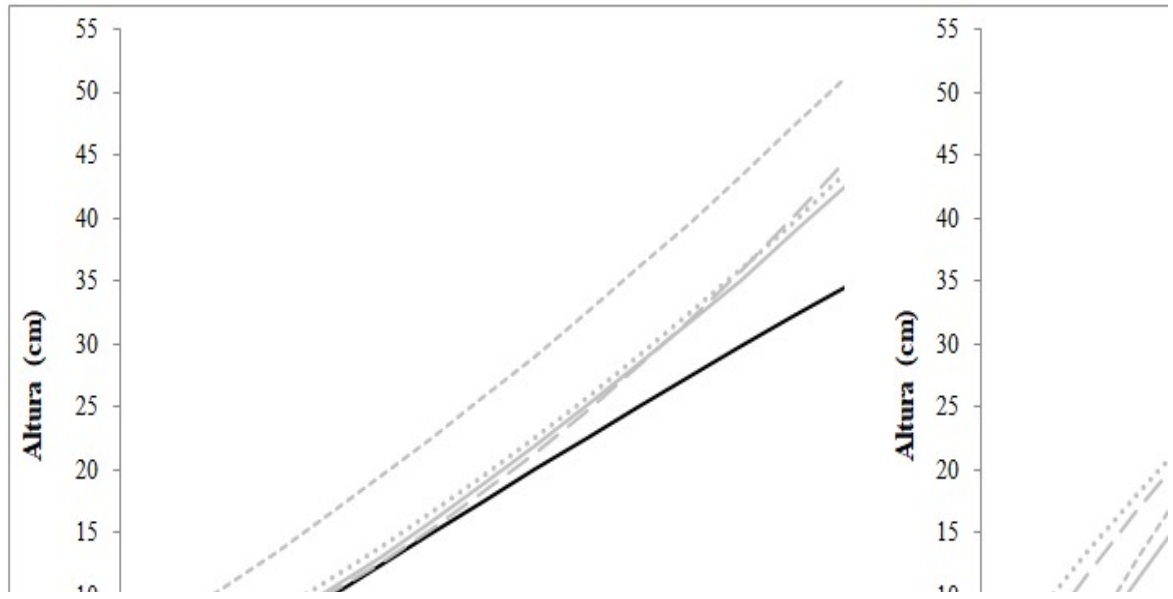

Figura 2: Curvas de crescimento das mudas de feijão sob as concentrações de compostagem em função do tempo. (A) compostagem a base bovina; (B) compostagem a base de serrapilheira.

É possível destacar que os compostos apresentaram sempre melhores desempenhos, quando comparadas a testemunha (areia), assim demonstra que para melhor produção de mudas de feijão é essencial uma adubação com o uso de compostagem. A aplicação do composto ocasiona maior produção nas plantas devido à melhoria de propriedades físicas e químicas do solo quando aplicado em pequenas concentrações, além disso, por se tratar de um resíduo com aspecto sólido, acredita-se que os efeitos de uma possível lixiviação também tenham sido reduzidos no substrato, possibilitando um estoque de nutrientes por um período maior para a planta (MOREIRA et al., 2019).

De acordo com Schwengber et al. (2007), para propiciar a incorporação de nutrientes no solo, o material utilizado na compostagem laminar não deve ser incorporado diretamente no solo sem estar 
completamente decomposto, pois nesse caso poderiam ocorrer fermentações anaeróbias, envolvendo o consumo do nitrogênio presente no solo. Para Ferreira et al. (1995), com a agregação da serapilheira no solo, tende a ter um aumento da oferta direta de nutrientes que entram em sua composição muito mais rápida, favorecendo disponibilização mais rápida dos nutrientes presentes na compostagem.

Em relação às concentrações, a linha de tendência demonstrou que a curva de crescimento apresentou crescimento máximo entre as concentrações de 50 a 75\% para os dois sistemas de compostagem, portanto a utilização do composto puro diretamente para a produção não garante melhor desenvolvimento, sendo necessária sua diluição (Figura 3).

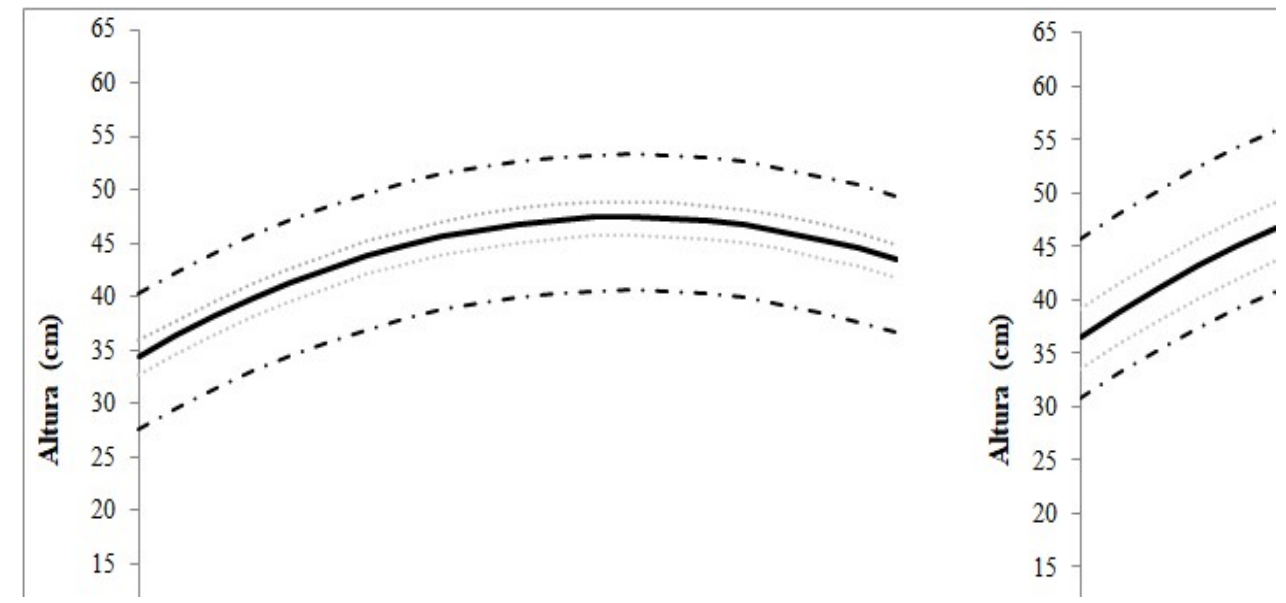

Figura 3: Curvas de crescimento das mudas de feijão sob o tipo de compostagem em serrapilheira unção das concentrações. (A) compostagem a base bovina; (B) compostagem a base de serrapilheira.

Nos estudos de Moreira et al. (2019), analisando o efeito de diferentes concentrações de compostos orgânicos sobre o crescimento de plantas de girassol, concluíram que a concentração de $50 \%$ do material orgânico utilizado obteve melhor produtividade quando comparadas a maiores concentrações do composto, podendo se tornar uma alternativa como fertilizante para o solo.

Nos estudos de Tecchio et al. (2005) foram observados o efeito positivo do esterco de curral (bovino) no crescimento de plantas, evidenciando melhor distribuição das raízes. Ferreira et al. (1995) relataram que o material resultante da serapilheira exerce inúmeras funções no equilíbrio de crescimento das plantas, podendo ser usado no solo em ambientes florestais, agriculturas e vários outros.

Santos et al. (2004) avaliaram a influência da adubação orgânica e mineral no crescimento de plantas, da qual concluíram que a adubação orgânica, é recomendada para plantas medicinais, aromáticas e plantio de lavouras como de feijões milhos e entre outras, visando produtos em quantidade e qualidade, com segurança para a saúde humana, animal e do meio ambiente. Ainda segundo os autores, para o cultivo de culturas agrícolas o uso de compostos orgânicos como fonte principal de adubação promove considerável aumento no crescimento das plantações em consequência de melhorias nas propriedades físicas e químicas do solo.

\section{CONCLUSÕES}

Para melhorar a fertilidade do solo é recomendável uso de compostagem como fonte nutricional, 
principalmente no cultivo de Vigna unguiculata. Conforme análise dos resultados obtidos se observa que a compostagem à base de serrapilheira apresentou melhor desenvolvimento para o vegetal. Dessa forma o uso do composto orgânico a base de serapilheira trará maior desenvolvimento para o cultivo de vegetal, principalmente para a Vigna unguiculata conforme estudo.

\section{REFERÊNCIAS}

DUARTE, D. H. S.; SERRA, G. G.. Padrões de ocupação do solo e microclimas urbanos na região tropical continental Brasileira: correlações e proposta de um indicador. Ambiente Construído, Porto Alegre, v.3, n.2, p.7-20, 2003.

ECOLE, C. C.; MALIA, H. A. E.; SOUZA, R. B.; RESENDE, F. V.. Compostagem e Adubos Orgânica. Horticultura. In: HABER, L. L.; CARVALHO, C. E.; BOWEN, W.; RESENDE, F. V.. Horticultura em Moçambique: características, tecnologias de produção e de pós-colheita. Brasília: Embrapa, 2015. p.93-99.

EWEL, J. J.. Queda de folhas e decomposição foliar em uma sucessão de florestas tropicais no leste da Guatemala. Jornal da Ecologia, v.64, p.293-308, 1976.

FERREIRA, C. A.; SILVA, H. D.; BELLOTE, A. F. J.; ANDRADE, G. C.. Efeito da aplicação de cenografia e resíduos de celulosa na decomposição e libertação de nutrientes da hojarasca em plantações de Eucalyptus grandis. Bosque, Valdivia, v.16, n.1, p.101-104, 1995.

HIGA, T.; WIDIDANA, G. N.. Changes in the soil micoflora induced by effective microrganism. In: INTERNATIONAL CONFERENCE ON KYUSEI NATURE FARMING, 1. Anais. Washington: Agricultural Research Service, 1991. p.153-162.

KIMOTO, T.. Nutrição e adubação de repolho, couve-flor e brócolis. In: FERREIRA, M. E.; CASTELLANE, P. D.; CRUZ, M. C. P.. Nutrição e adubação de hortaliças. Piracicaba: Potafos, 1993. p.149-178.

KONZEN, E. A.; ALVARENGA, R. C.. Fertilidade de solos: adubação orgânica. In: CRUZ, J. C.. Cultivo do milho. 5 ed. Sete Lagoas: Embrapa Milho e Sorgo, 2009.

LARCHERL, W.. Ecofisiologia vegetal. São Carlos: Rima, 2000.

MARINHO, N. F.; CAPRONI, A. L.; FRANCO, A.; BERBARA, R. L. L.. Respostas de Acácia mangium Willd e Sclerolobium paniculatum Vogel a fungos micorrízicos arbusculares nativos provenientes de áreas degradadas pela mineração de bauxita na Amazônia. Acta Botânica Brasileira, São Paulo, v.18, n.1, p.141-149, 2004.

MOREIRA, L. M.; MOURA, L. F.; ALMEIDA, F. B. B.; PONTESFILHO, R. A.; GONDIM, F. A.. Efeitos de diferentes concentrações de resíduo industrial de suplemento mineral para animal sobre o crescimento de plantas de girassol. Revista Brasileira de Agroecologia, v.14, n.1, p.3-8, 2019.
OLIVEIRA; A. M. G.; AQUINO; A. M.; NETO; M. T. C. Compostagem Caseira de Lixo Orgânico Doméstico. Circular técnico n.76. Salvador: Ministério da Agricultura Pecuária e Abastecimento, 2005

PEREIRA NETO, J. T.; STENTIFORD, E. I.. Aspectos epidemiológicos da compostagem. Revista de Biologia, Uberlândia, v.1, n.1, p.1-6, 1992.

R CORE TEAM. R: Uma linguagem e ambiente para computação estatística. Viena: R Fundação para Computação Estatística, 2019.

SANTOS, M. R. A.; INNECCO, R.. Adubação orgânica e altura de corte da erva-cidreira brasileira. Horticultura Brasileira, v.22, n.2, p.182-185 2004

SANTOS, M. V. F.; LIRA, M. A.; BURITY, H. A.; FARIAS, I.; SANTOS, M. E. P.; NASCIMENTO, M. M. A.. Número, dimensões e composição química de artículos de palma forrageira (Opuntia ficus-indica, Mill) cv. gigante, de diferentes ordens. Pesquisa Agropecuária Pernambucana, Recife, v.7, p.69-79, 1990.

SCHWENGBER, J. E.; SCHIEDECK, G.; GONÇALVES, M. M. Compostagem laminar: uma alternativa para o manejo de resíduos orgânicos. Comunicado técnico n.169. Rio de Janeiro: Embrapa Clima Temperado, 2007

SILVA, J.; SILVA, P. S. L.; OLIVEIRA, M.; SILVA, K. M. B.. Efeito de esterco bovino sobre os rendimentos de espigas verdes e de grãos de milho. Horticultura Brasileira, Brasília, v.22, n.2, p.326-331, 2004

SOUTO, P. C.; SOUTO, J. S.; SANTOS, R. V.; ARAÚJO, G. T.; SOUTO, L. S.. Decomposição de estercos dispostos em diferentes profundidades em área degradada no semiárido da Paraíba. Revista Brasileira de Ciência do Solo, v.29, n.1, p.125-130, 2005

TECCHIO, M. A.; DAMATTO JUNIOR, E. R.; LEONEL, S.; PEDROSO, C. J.. Distribuição do sistema radicular do maracujazeiro-doce cultivado com adubação química e orgânica. Revista Brasileira de Fruticultura, v.27, n.2, p.75664, 2005.

TEIXEIRA, R. F. F.. Compostagem. In: HAMMES, V. S. Educação ambiental para o desenvolvimento sustentável. Brasília: Embrapa Informação Tecnológica, 2002. p.120-123.

A CBPC - Companhia Brasileira de Produção Científica (CNPJ: 11.221.422/0001-03) detém os direitos materiais desta publicação. Os direitos referem-se à publicação do trabalho em qualquer parte do mundo, incluindo os direitos às renovações, expansões e disseminações da contribuição, bem como outros direitos subsidiários. Todos os trabalhos publicados eletronicamente poderão posteriormente ser publicados em coletâneas impressas sob coordenação da Sustenere Publishing, da Companhia Brasileira de Produção Científica e seus parceiros autorizados. Os (as) autores (as) preservam os direitos autorais, mas não têm permissão para a publicação da contribuição em outro meio, impresso ou digital, em português ou em tradução. 